\title{
CLUSTERS E SUA ADAPTAÇÃO ÀS CADEIAS GLOBAL DE VALOR (CGVS)
}

\author{
Violeta de Faria Pereira ${ }^{1}$
} Cláudia Andreoli Galvão ${ }^{2}$

Resumo: A partir de 1970, a produção fragmentou-se internacionalmente, minimizando custos, deslocando para os países de mão de obra abundante e barata as fases da produção mais trabalho-intensivas. Intensificam-se as redes globais apoiadas nos transportes, telecomunicações e tecnologia da informação. Pesquisa e desenvolvimento, design, fabricação e distribuição, remodelaram a produção em CGVs, forçando os distritos industriais (DIs)/clusters a se adaptarem, mudarem, reinvestirem ou declinarem. Assim, via revisão bibliográfica, buscou-se responder à pergunta se os DIs/clusters perderiam ou ganhariam relevância na globalização. Os distritos italianos mudaram sua especialização de bens finais para bens de capital, com um terço das empresas se transferindo para a indústria mecânica em atividades correlatas, explorando suas conexões com as CGVs, coordenando fornecedores, se reorientando para produtos de alta qualidade, aumentando investimentos em marketing e marcas. No caso brasileiro com o processo de reestruturação os Dls/clusters abandonaram as estratégias de redução de custos e passaram a inovar, aumentando a importação de bens intermediários e utilizando a terceirização e a relocalização de fábricas para o nordeste brasileiro. Os distritos italianos estão cada vez mais ligados às CGVs, enquanto os brasileiros se ligam às cadeias nacionais, e só marginalmente se conectam às CGVs em redes de governança. Assim, os DIs/clusters não perderam relevância na globalização, antes eles buscaram novas maneiras de produzir, flexibilizando, respondendo ao mercado consumidor, buscando qualidade, via tecnologia, diferenciando os produtos, utilizando a terceirização, negociando com fornecedores, fabricando lotes menores. Nesse contexto os DIs/clusters analisados sobreviveram e estão atuantes no mercado.

Palavras-chave: Cadeias Globais de Valor. Distritos Industriais. Clusters. Globalização. Reestruturação Produtiva.

\section{CLUSTERS AND THEIR ADAPTATION TO GLOBAL VALUE CHAINS}

Abstract: Since 1970, production has fragmented internationally, minimizing costs, shifting the more labor-intensive stages of production to the countries of abundant and cheap labor. Global networks based on transport, telecommunications and information technology are intensifying. Research and development, design, manufacture and distribution, have reshaped production in Global Value Chains (GVCs), forcing industrial districts(IDs)/clusters to adapt, change, reinvest or decline. Thus, via a bibliographic review, we sought to answer the question whether IDs /clusters would lose or gain relevance in globalization. Italian districts changed their specialization from final goods to capital goods, with one third of the enterprises moving to the mechanical industry in related activities, exploring their connections with GVCs, coordinating suppliers, redirecting themselves to high quality products, increasing investments in marketing and brands. In the Brazilian case with the restructuring process, the clusters abandoned the cost reduction strategies and started to innovate, increased the import of intermediate goods and used the outsourcing and relocation of factories to the Brazilian Northeast. Italian districts are

\footnotetext{
1 Universidade de Brasília; Departamento de Geografia; Brasília; Brasil; violetafariapereira@gmail.com; https://orcid.org/0000-0002-7329-2580

2 Universidade de Brasília; Departamento de Geografia; Brasília; Brasil; claudiaandreoli@gmail.com; https://orcid.org/0000-0002-5581-4103
} 
increasingly connected to GVCs, while Brazilians are linked to national chains, and only marginally connect to GVCs in governance networks. Thus, IDs /clusters have not lost relevance in globalization, instead industrial districts/clusters sought new ways of producing, making them more flexible, responding to the consumer market, seeking quality through advanced technology, differentiating products, using outsourcing, negotiating with suppliers, manufacturing smaller batches. In this context, the analyzed IDs/clusters survived and are active in the market.

Keywords: Global Value Chains. Industrial Districts. Clusters. Globalization. Productive Restructuring.

\section{CLUSTERS Y SU ADAPTACIÓN A LAS CADENAS GLOBALES DE VALOR (CGVs)}

Resumen: Desde 1970, la producción se ha fragmentado internacionalmente, minimizando los costos, desplazando las fases de la producción más intensivas en mano de obra a los países onde és abundante y barata. Las redes mundiales basadas en el transporte, las telecomunicaciones y la tecnología de la información se están intensificando. La investigación y el desarrollo, el diseño, la fabricación y la distribución han reformado la producción en CGVs, obligando a los distritos industriales (DIs)/clusters a adaptarse, cambiar o declinar. Así, por revisión bibliográfica, buscamos responder la pregunta de si los DIs/Clusters perderían o ganarían relevancia en la globalización. Los distritos italianos cambiaron su especialización de bienes finales a bienes de capital, se trasladando a la industria mecánica en actividades relacionadas, explorando sus conexiones com las CGVs, coordinando proveedores, redirigiéndose a productos de alta calidad, aumentando las inversiones en marketing y marcas. En el caso brasileño con el proceso de reestructuración, los clusters abandonaron las estrategias de reducción de costos y comenzaron a innovar, aumentaron la importación de bienes intermedios y utilizaron la subcontratación y la reubicación de fábricas para el noreste de Brasil. Los distritos italianos están cada vez más vinculados a las CGVs, mientras que los brasileños están vinculados a las cadenas nacionales. Así, los Dls/clusters no han perdido relevancia en la globalización, antes buscaran nuevas formas mas flexíveis de producción, buscando calidad por tecnología, diferenciando productos, fabricando lotes pequeños. Por fin, los Dls/clusters sobrevivieron y están activos.

Palabras clave: Cadenas globales de valor. Distritos Industriales. Clusters. Globalización. Reestruturación productiva.

\section{INTRODUÇÃO}

A partir dos anos 1970, a produção se fragmentou internacionalmente minimizando os custos totais, assim os segmentos do processo produtivo mais intensivos em trabalho não qualificado se reterritorializam para países periféricos onde esse fator é abundante e barato. Nesse novo paradigma que configura o capitalismo global se intensificam as redes globais apoiadas no desenvolvimento dos transportes e das telecomunicações, na evolução da tecnologia de informação, que permite a fragmentação e padronização de tarefas, incluindo assim muitos países periféricos. $\mathrm{O}$ aumento da pressão sindical por salários mais altos e melhores 
condições de trabalho nas economias desenvolvidas contribuiram para deslocar partes ou todo o processo produtivo para países em desenvolvimento.

Os Distritos Industriais (DIs)/Clusters têm enfrentado sucessivas crises econômicas de forma inovadora, avançando na especialização produtiva em regiões ou locais determinados, principalmente nos países emergentes. Eles buscam a eficiência coletiva por meio da proximidade geográfica das empresas, na troca de bens e serviços e na cooperação dos agentes econômicos. O resultado é uma maior competitividade. Quando o Cluster atinge seu estágio mais avançado ele toma a forma do Distrito Industrial.

Esse trabalho buscou identificar como os DIs/Clusters se ajustam às cadeias globais de valor (CGVs). Para atingir esse objetivo foi feita uma revisão teórica sobre DIs/Clusters e CGVs, bem como buscou-se analisar as respostas de alguns DIs/Clusters a esse reajuste no modo de produção global, revisando alguns autores que analisaram as mudanças que se operaram em alguns distritos industriais italianos e alguns clusters brasileiros.

Iniciamos a discussão analisando as cadeias globais de valor, seguimos analisando os DIs/Clusters, onde discorremos sobre suas características. Continuamos a discussão com os Dls Italianos e suas transformação frente à globalização, depois discutimos os Clusters brasileiros e suas transformações frente à globalização. Finalizamos com as Considerações finais.

\section{AS CADEIAS GLOBAIS DE VALOR (CGVs)}

Para Ascani, Crescenzi e Immarino (2012) a globalização evoluiu da produção em massa para sistemas de produção mais flexíveis, respondendo à pressão da concorrência. Assim, a produção estandardizada tornou-se progressivamente obsoleta em favor de um sistema especializado e mais flexível às mudanças, o que permitiu às empresas sobreviver à incerteza global. As cadeias globais têm em seu topo intensa concentração de empresas líderes e fornecedores globais de alta qualificação. Na base da cadeia ocorre a fragmentação por meio de franquias, subcontratações e parcerias.

Para Gereffi (2015), nas últimas décadas, mudanças na estrutura da economia global remodelaram a produção e o comércio e alteraram a organização de indústrias e economias nacionais em CGVs, aumentando o montante de bens intermediários e componentes exportados. Em 2009, as exportações mundiais de bens intermediários excederam os valores combinados de exportação de bens finais 
e de capital. Gereffi (2015) referindo-se ao período posterior a 1989, com o colapso da União Soviética, a abertura da China ao comércio internacional e a liberalização da Índia, relatou que um grande número de economias conhecidas como BRICs (Brasil, Rússia, Índia e China) entrou no cenário global, o que resultou no que Richard Freeman chamou de "a grande duplicação" da mão de obra global, de cerca de 1,5 bilhão para 3 bilhões de trabalhadores (Freeman, 2008, apud Gereffi, 2015: 2). As CGVs concentraram suas operações de investimento e fornecimento em economias emergentes grandes e dinâmicas que ofereciam matérias-primas abundantes, trabalhadores de baixa remuneração, fabricantes altamente capacitados e mercados domésticos em crescimento.

As sete economias emergentes (China, Índia, Brasil, México, Rússia, Coréia do Sul e África do Sul) estão todas envolvidas em tipos distintos de CGVs. Elas respondiam por $45 \%$ da população mundial, $25 \%$ das exportações mundiais e $24 \%$ do produto interno bruto (PIB) em 2013, e suas taxas de crescimento do PIB se mostravam superiores à média mundial $(3,2 \%$ versus $2,2 \%)$ (Freeman, 2008, apud Gereffi, 2015: 3).

Para Zhang e Schimanski (2014) a cadeia de valor de um bem é composta por atividades inter-relacionadas no ciclo produtivo, desde a pesquisa e desenvolvimento, design e fabricação, até a distribuição. Para eles nas CGVs os bens são produzidos com insumos provenientes de diferentes países e, consequentemente, as exportações de um país dependem cada vez mais do valor acrescentado pelas indústrias fornecedoras. Além disso, as exportações de um país contêm cada vez mais valor estrangeiro adicionado, via importações de insumos ou produtos intermediários.

Zhang e Schimanski (2014) lembram que embora a cadeia global de valor não possa ser considerada um fenômeno inteiramente novo, a sua velocidade, sua escala e sua complexidade aprofundaram a globalização econômica, por meio da inclusão de mais países, inclusive os em desenvolvimento. A globalização se aprofundou setorialmente, ao afetar a produção e os serviços, e funcionalmente, incluindo não só a produção e distribuição, mas também a pesquisa e a inovação. Zhang e Schimanski (2014:84) apresentam dados demonstrando que os produtos intermediários compreendem o mais importante fluxo de comércio da atualidade: aproximadamente $40 \%$ do total comercializado (mais de US\$ 7 trilhões em 2011).

Gereffi e Frederick (apud Zhang e Schimanski, 2014) observaram que os países em desenvolvimento se concentram nas atividades intensivas em trabalho, 
enquanto as economias desenvolvidas nas atividades mais valiosas dessa cadeia, ou seja, design, desenvolvimento da marca e marketing.

\section{OS DISTRITOS INDUSTRIAIS (DIS)/CLUSTERS}

A importância das aglomerações foi resgatada de Marshall que enfatiza que os segredos da profissão deixam de ser segredos e ficam soltos no ar, formando uma atmosfera industrial (Dei Ottati,1991). O distrito industrial se constitui em um aglomerado de pequenas empresas baseadas na produção flexível, especializadas em um segmento produtivo apresentando um crescimento bastante dinâmico.

A Terceira Itália exemplificou o dinamismo baseado na eficiência coletiva para um aglomerado de pequenas e médias empresas localizadas próximas umas das outras, em atividades conjuntas, ganhando em competitividade, apoiadas pelas instituições locais.

O enraizamento das atividades econômicas nas relações sociais permite a troca repetida sobre um período de tempo que encoraja a reciprocidade, facilitando a resolução dos dilemas da ação coletiva. A habilidade em cooperar é um dos mais importantes atributos dos clusters. Dei Ottati (1991) analisou o comportamento oportunístico nos DIs e afirmou que ele pode ser desestimulado quando existe contato permanente entre as pessoas, resultando em contratos informais, identificando os comportamentos oportunistas que reduzem a eficiência econômica e aumentam os custos transacionais. Nos DIs os conflitos serão resolvidos de uma forma menos onerosa, sem contratos nem burocracia. Quando uma transação é incerta ou ambígua devido à interdependência ou à inovação, não ocorrerão custos adicionais para a busca de mais informações porque elas estarão disponíveis na comunidade.

A cooperação entre as empresas é crucial, uma vez que a inovação é um processo cumulativo, que envolve aprender na prática, no uso diário e na interação entre os agentes gerando rendimentos crescentes. O processo inovativo nos Dls é estimulado de duas formas: a) pela desintegração vertical ou o fracionamento do processo produtivo, fazendo com que as novas e antigas ideias se combinem e produzam novos resultados; b) pelo incentivo à cooperação porque os processos de produção e inovação estão distribuídos entre as empresas, permitindo a partilha do processo inovativo. Dei Ottati (1991) mostra que a competição promove eficiência nos Dls, reduzindo os riscos para as novas empresas ou para o investimento em novos maquinários e produtos. Ela mostra que o fracionamento do processo 
produtivo resulta na distribuição dos investimentos e dos riscos entre as empresas do distrito.

Knorringa e Meyer-Stamer (1998) salientam que os retornos de escala são crescentes devido ao grande número de empresas e pesquisadores aperfeiçoando a tecnologia. O pool de mão de obra local e de especialistas altamente qualificados é uma das vantagens nos clusters. A especialização se tornará um bem público, pois se difunde por meio da vida cotidiana. O conhecimento, no distrito, ocorre por meio de relações face a face. Por outro lado, para as empresas será mais fácil e mais barato avaliar a qualificação de cada trabalhador, por estarem enraizadas na comunidade.

\section{DISTRITOS INDUSTRIAIS (DIs) ITALIANOS E SUAS TRANSFORMAÇÕES FRENTE À GLOBALIZAÇÃO}

Dei Ottati (2016) destacou o importante papel desempenhado pelos DIs na economia italiana e analisou os processos evolutivos do Distrito Industrial Marshalliano na era da globalização. Para ela, a deslocalização do processo de produção começou com as empresas transnacionais dos países mais industrializados e passou a incluir pequenas e médias empresas dos países emergentes. Esta autora enfatizou que alguns dos processos de produção permaneceram nos países desenvolvidos, como a produção de séries curtas, a produção de bens com prazos curtos de entrega, o design e o marketing.

Quanto à evolução dos Dls italianos, ela mostra que as economias externas passaram a não ser suficientes no contexto da globalização, da liberalização e das novas formas de tecnologia de comunicação. Desta forma, o processo passou a se basear em CGVs, organizadas por meio da fragmentação internacional dos processos de produção. A referida autora descobriu que, as relações interindustriais no local não desapareceram com a globalização, pelo contrário, enriqueceram, estendendo nichos de mercado em nível global.

Dei Ottati (2016) afirmou que, com o advento da globalização, muitas pequenas empresas não conseguiram sobreviver nos Dls italianos, algumas se recuperaram, introduzindo inovação em produtos, processos e organização da produção e na comercialização, recuperando sua vantagem competitiva. Ela também afirmou que a concentração do sistema de distribuição, mudou o equilíbrio de poder para os grandes compradores que passaram a obter suprimentos em países de baixo custo de mão de obra. 
Accetturo et al. (2013, apud Giuliani e Rabellotti, 2018:23) afirmam que o desempenho dos Dls varia amplamente: os Dls dos setores tecnológicos têm tido melhores desempenhos com tendências positivas estáveis no emprego, no período 1993-2008, enquanto, no mesmo período, a tendência dos Dls "Made in Italy", geraram poucos postos de trabalho.

Foi observada, no estudo de Giuliani e Rabellotti (2018), uma tendência dos DIs de alterar sua especialização. Hidalgo et al. (2007, apud Giuliani e Rabellotti, 2018) relatam evidências sistemáticas de países e regiões se diversificarem em setores que estejam relacionados às suas atividades históricas. Essa diversificação dependente de sua trajetória, decorre da reutilização e adaptação das capacidades e ativos tecnológicos, do conhecimento, das relações organizacionais e comerciais existentes. Em resposta à ampliação das oportunidades de mercado para novos países, vários Dls italianos mudaram sua especialização em bens finais, como roupas e calçados, caracterizados pela competição baseada em custos, para bens de capital, como máquinas para a indústria de vestuário e calçados. Giuliani e Rabellotti (2018:23-24) relatam que entre 1991 e 2001, 21(vinte e um) DIs italianos mudaram sua especialização industrial, com um terço se transferindo para a indústria mecânica em atividades correlatas. Elas pontuam que desde a década de 1990, as empresas exportadoras dos DIs melhoraram a qualidade de seus produtos. As autoras exemplificam com o cluster de Biella, onde algumas empresas locais assumiram papéis de liderança nas CGVs, reorientando sua produção para tecidos de luxo de alta qualidade e aumentando seus investimentos em marketing e marcas.

Bugamelli et al. (2010, apud Giuliani e Rabellotti, 2018) mostram que a pressão da concorrência chinesa é mais expressiva em setores de baixa qualificação, como têxtil, vestuário, artigos de couro e móveis, setores esses onde a competição é mais severa para empresas menos produtivas, menos capazes de responder com estratégias de atualização e especialização.

Giuliani e Rabellotti (2018) relatam que os DIs italianos conseguiram obter diferenciação de sua produção por meio da reorganização das atividades como estratégia de escapar da armadilha de baixo custo e baixo valor agregado, explorando suas conexões com as CGVs. As autoras explicam que os Dls italianos responderam à incerteza de um cenário global de produção e inovação, dedicando recursos a atividades de pesquisa ou design e, em alguns casos, se tornaram líderes internacionais. 


\section{CLUSTERS BRASILEIROS E SUAS TRANSFORMAÇÕES FRENTE À GLOBALIZAÇÃO}

Galvão (1999) analisando o complexo manufatureiro calçadista do Vale do Sinos no Rio Grande do Sul, mostra que esse complexo podia ser considerado um autêntico distrito industrial, por se tratar de uma aglomeração de pequenas e médias empresas, produzindo um produto específico, em uma área geográfica determinada, com um fluxo intenso de informações, alta densidade institucional, com a presença de fornecedores de insumos e peças, e fortes valores familiares e sociais.

Como a inserção de clusters em CGVs pode ter efeitos positivos e negativos sobre sua capacidade competitiva, Meyer-Stamer, Maggi e Seibel (2001, apud Silva e Garcia, 2005) estudaram os desafios dos clusters industriais à globalização. Eles examinaram os mecanismos pelos quais os clusters constroem vantagens competitivas locais por meio do upgrading de produtos e processos. O cluster cerâmico da região de Criciúma, em Santa Catarina, conseguiu o upgrading em seus produtos, aumentando sua relevância no mundo, ao lado de Castellón, na Espanha, e Sassuolo, na Itália. Na comercialização, inclusive on line, as empresas brasileiras estão à frente das italianas e espanholas.

Silva e Garcia (2005) estudaram dois clusters de revestimentos cerâmicos, um em Criciúma em Santa Catarina e outro em Santa Gertrudes, São Paulo, ressaltando as semelhanças e diferenças de estratégias adotadas, analisando o papel da inovação e da busca pela diferenciação do produto por meio do design. Para esses autores o padrão de concorrência do setor de revestimento cerâmico organiza-se em torno do preço, da qualidade e da diferenciação do produto e que as empresas de cerâmica devem considerar a resistência, a impermeabilidade, a funcionalidade e a beleza (design) na busca por competitividade. Seguem afirmando que os fornecedores de equipamentos, principalmente italianos, e de insumos básicos como os coloríficos espanhóis têm um papel relevante nas inovações levando a vantagens competitivas.

Silva e Garcia (2005) relatam que a abundância de matéria-prima natural, fontes alternativas de energia e disponibilidade de tecnologias fizeram com que as empresas brasileiras evoluíssem para produtos de qualidade mundial. Nesse estudo os autores mencionam que o tamanho do mercado nordestino e os custos de transportes associados ao baixo valor agregado dos revestimentos cerâmicos levou à desconcentração regional da produção, para a Região Nordeste. Silva e Garcia (2005) narram que o cluster de Criciúma (SC) e o de Santa Gertrudes (SP) 
apresentam trajetórias distintas competindo no mercado interno. Em geral, a cerâmica catarinense é mais sofisticada e mais cara que a de Santa Gertrudes. O cluster de Criciúma é responsável por cerca de um terço da produção nacional e dois terços das exportações (Meyer-Stamer e Seibel, 2002, apud Silva e Garcia, 2005:3640), enquanto o de Santa Gertrudes, responde por cerca de 50\% da produção nacional e $15 \%$ do total das exportações (Ferraz, 2002, apud Silva e Garcia, 2005:3640).

No início da década de 1990, o setor enfrentou uma crise de demanda e adotou a estratégia de modernização, aumentando a capacidade produtiva a taxas superiores à média nacional, via aquisição, instalação de novas plantas e modernização das pré-existentes, aumentando a produtividade.

A partir dos anos 1990, a estratégia competitiva baseada em preços foi abandonada, devido ao lento crescimento da demanda interna e do aumento da capacidade produtiva das empresas de Santa Gertrudes (SP). As empresas catarinenses perceberam a ameaça dos produtores de Santa Gertrudes cujos preços eram mais competitivos, embora a qualidade de seus produtos e o segmento de mercado em que atuavam funcionassem como proteção para suas posições de mercado.

Para Silva e Garcia (2005) a crise dos anos 1990 pediu a redefinição das estratégias competitivas, assim, as empresas do cluster passaram a buscar novas vantagens competitivas ao alterar, priorizar e investir em estratégias de marketing, de vendas e de distribuição. A ênfase no mercado externo ganhou importância.

Vargas e Alberton (2009) analisaram as empresas estabelecidas no cluster cerâmico de Criciúma e seu entorno, na região sul catarinense, de 2000 a 2008. Eles identificaram modificações como a implantação do gás natural, novas tecnologias, a valorização cambial e a expansão da economia da China, que afetaram esta indústria na produção e na demanda. Eles pontuam que de 1990 a 2000, aprofundou-se a concorrência nesse setor. Para enfrentar essa situação foram implantadas inovações de produtos, processos e organizacionais, como fechamento de unidades, ampliação e abertura de novas plantas, fusões e aquisições e a importação de bens de produção da Itália e da Espanha, além da utilização de novos métodos de organização e a terceirização. A retração do mercado interno direcionou parte da produção do setor para o exterior. Paralelo a isto, a baixa taxa de câmbio incentivou a presença dos produtos chineses no Brasil, aumentando a concorrência interna e consequentemente baixando a rentabilidade no mercado interno. As 
empresas estabelecidas no cluster cerâmico de Criciúma passaram, então, a ter grande desenvolvimento se destacando na produção de produtos cerâmicos do país.

Com relação ao setor têxtil, foi analisado o arranjo produtivo de tricô de Monte Sião, localizado parte em São Paulo e parte em Minas Gerais, que experimentou um crescimento econômico substancial nos anos 1990. Esse crescimento incentivou a ocorrência de grandes fluxos migratórios de mão de obra especializada, criando excedentes. Ocorreu, igualmente, a abertura de centenas de novas iniciativas que provocou excessivo fornecimento de confecções de malhas resultando na queda dos preços, reduzindo-se, assim, a remuneração da força de trabalho e o número de empresários. No início dos anos 2000, no entanto, Monte Sião superou essa fase por meio da reestruturação produtiva. As iniciativas não estruturadas tenderam a desaparecer e as pequenas empresas familiares aumentaram os investimentos em design e moda, oferecendo produtos diferenciados a novos nichos de mercado e, ocasionalmente, fornecendo peças para grandes marcas e redes nacionais. Monte Sião conseguiu superar seus problemas seguindo as tendências do setor de moda de Paris e Milão, e os relacionamentos que tinha com esse setor. Com a oferta de roupas de tricô em novos materiais e tecidos sintéticos, a cidade manteve os fluxos de turistas e comerciantes, garantindo a manutenção da atividade econômica. As malharias do cluster abastecem as lojas da própria cidade, as das cidades vizinhas e as de São Paulo, Belo Horizonte, Rio de Janeiro e região Sul do país.

Sevegnani e Sacomano (2008) pesquisaram mais de 20 (vinte) malharias evidenciando a pujança econômica do cluster, estudando as estratégias adotadas no processo produtivo, na tecnologia e nas estratégias industriais e competitivas. Esse cluster possui representação da indústria de máquinas têxteis mundial, atuando nas vendas, manutenção, instalação e treinamento. Uma estratégia utilizada é a aliança com grandes magazines que orientam as malharias sobre os modelos e a qualidade.

Muitas malharias utilizaram a terceirização, melhor negociação com fornecedores e redução de custos de produção. Grande parte das malharias no cluster trabalham com peças simples de tricô, vendidas ao público de menor renda. Essas malharias tiveram que enfrentar a concorrência chinesa, sendo que muitas delas encerrarem suas operações ou se transformaram em fornecedores de malharias maiores. Outras malharias investiram em modernização de máquinas, treinamento, informatização, fabricando produtos com maior qualidade, e mais detalhes, gerando maior produtividade e maior valor agregado, minimizando custos e maximizando lucros. Sevegnani e Sacomano (2008) concluíram que houve 
grandes mudanças no cenário brasileiro industrial após a abertura econômica de 1990. Isso demandou muita habilidade das malharias, no sentido de buscar novas maneiras de produzir para se diferenciarem, sobreviverem e continuarem atuantes no mercado.

Destaca-se, também, no cenário brasileiro o cluster calçadista do Vale do Sinos, no Rio Grande do Sul, responsável pela maior fatia da produção brasileira de calçados, destinada a mercados no exterior. Costa (2009) empreendeu um estudo para tentar elucidar a direção que seguiram os ajustes empreendidos por empresas brasileiras de calçados e instituições vinculadas ao setor, nesse cluster. $O$ argumento central desse autor é que frente aos novos desafios competitivos é preciso considerar não só a organização industrial, mas também a história da sua inserção no mercado internacional e os fatores que têm determinado a dinâmica competitiva dessa atividade. Ele enfatiza que a produção de calçados no Brasil até o final da década de 1960 esteve associada ao mercado interno, com produtos compatíveis com a renda capita baixa. A dimensão continental do país e o tamanho da população, por sua vez, permitiram a sobrevivência de uma estrutura industrial de certa magnitude que somadas à difusão da arte de fabricação de calçados constituíram uma organização produtiva formada por pequenas e médias empresas, em aglomerações no espaço geográfico. Nesse cenário se destacava a manufatura com marcadas características artesanais, fabricando os seus próprios componentes.

Esse autor relata que a partir do final da década de 1960, a produção de calçados se expande no mercado externo, incorporando baixos salários e oferta abundante de mão de obra, incentivos fiscais e financeiros e taxa de câmbio favorável; além da presença de uma estrutura produtiva mínima que garantiu a efetividade da produção.

Para esse autor, a partir dos anos 1990, a indústria se defronta com pressões competitivas oriundas do surgimento de novos concorrentes que se beneficiam de custos mais baixos de produção, devido à vantagem comparativa do preço de sua mão de obra, assim torna-se cada vez mais problemática a sua sustentação no exterior. Costa (Op. cit.) segue relatando que de 1990 até 1999 o setor de calçados brasileiro entra em declínio, devido à forte valorização da taxa de câmbio em decorrência do programa de estabilização da economia (Plano Real) e juros elevados cujo resultado é a perda de competitividade dos calçados brasileiros nos mercados interno e externo. 
Esse autor segue argumentando que o país assistiu à penetração de calçados chineses no mercado doméstico e à demissão de milhares de trabalhadores, no Vale do Sinos, o que levou o setor a adotar ajustes, mesclando modernização produtiva, demanda por proteção comercial e deslocamento de unidades de produção em direção ao nordeste brasileiro, em função dos incentivos fiscais, financeiros e do custo da mão de obra. Costa (Op. cit.) lembra que a participação dos calçados no seu principal mercado, os Estados Unidos, tem declinado diante da produção chinesa baseada em preço. Para ele as grandes empresas buscam atuar com marca própria, se diferenciar no mercado mediante o design, diversificando mercados no exterior, vendendo diretamente para o importador final, via subcontratação.

A deslocalização para o Nordeste mostrou-se positiva, os investimentos tiveram um efeito multiplicador na competitividade, criando melhores condições para a produção e difusão de tecnologias modernas. Esse autor enfatiza que a adaptação ao quadro de mudanças também ocorre com as pequenas e médias empresas, que têm limitações financeiras e de organização, elas já percebem a importância de incorporar o design como uma ferramenta e já colocam produção com sua marca em países da América Latina.

\section{CONSIDERAÇÕES FINAIS}

Os DIs italianos encontraram formas de reproduzir algumas das suas forças internas e combiná-las com novos fatores, introduzindo inovação em produtos, processos, na organização da produção e na comercialização, recuperando a vantagem competitiva. Vários Dls italianos mudaram a sua especialização de bens finais para bens de capital, como máquinas. Muitas empresas assumiram papéis de liderança nas CGVs, coordenando fornecedores locais e externos, reorientando sua produção e aumentando seus investimentos em marketing e marcas. Os Dls italianos responderam à incerteza de um cenário global por meio da diferenciação de sua produção e da reorganização de suas atividades. Assim, escaparam da armadilha de baixo custo e baixo valor agregado, explorando suas conexões com as CGVs, pesquisando e inovando.

Quanto aos clusters brasileiros, com o aumento da competição chinesa, os clusters de malhas foram obrigados a buscar novas maneiras de produzir para se diferenciarem. A competitividade e a globalização do mercado têm levado as empresas a aperfeiçoarem seus sistemas de fabricação, buscando a flexibilização na confecção de seus produtos, dando respostas rápidas ao mercado consumidor, 
buscando qualidade com menores custos, utilizando a estratégia de terceirização, negociando com os fornecedores, fabricando lotes menores de modelos diversificados. Nesse contexto muitas empresas sobreviveram e estão atuantes no mercado, as demais pereceram ou reduziram seus tamanhos a pequenas malharias que atendem às grandes ou vendem seus produtos diretamente no varejo. Utilizaram também a aliança com grandes magazines que orientam as malharias sobre os modelos e qualidade a serem alcançados. Nesse cluster ocorre a diferenciação do produto por intermédio de tecnologia mais avançada, que possibilita a fabricação de produtos mais elaborados, com maior valor agregado.

Já o cluster de revestimentos cerâmicos, em razão da retração do mercado interno, direcionou sua produção para o exterior. A baixa taxa de câmbio incentivou a presença dos produtos chineses no Brasil, aumentando a concorrência interna e consequentemente baixando a rentabilidade. No processo de reestruturação dos clusters de cerâmica, as empresas abandonaram as estratégias de redução de custos e obtenção de escala de produção e passaram a incorporar inovações de produtos, de processos e organizacionais, bem como passaram a importar bens de produção e a utilizar a terceirização, e estratégias de relocalização de fábricas para o nordeste brasileiro.

Por sua vez, o cluster de calçados se defrontou com pressões competitivas oriundas do surgimento de novos concorrentes que se beneficiaram com a vantagem do preço de sua mão de obra. A penetração de calçados chineses no mercado doméstico levou o setor a adotar uma estratégia de ajuste, mesclando modernização produtiva e deslocamento de unidades de produção em direção ao nordeste brasileiro

O surgimento das CGVs colocou os lugares em um espaço global em um período muito curto, forçando os DIs/Clusters a se adaptarem, mudarem, reinvestirem ou declinarem. Assim, eles estão renovando sua vantagem competitiva, combinando o antigo e o novo, o local e o regional, o nacional e o global. Em relação à inserção dos DIs/Clusters às CGVs podemos indicar que a tendência observada pelos estudos revisados mostra que os Dls italianos estão cada vez mais ligados às CGVs, enquanto os brasileiros se vinculam às cadeias de valor nacionais, e só marginalmente se conectam às CGVs em sua forma de rede com governança, embora se vinculem crescentemente no intercâmbio derivado das crescentes importações de bens de capital e via um crescimento ainda insipiente das exportações. 


\section{REFERÊNCIAS}

ASCANI, A.; CRESCENZI, R.; IMMARINO, Simona. Regional Economic Development: A Review. WP1/03 SEARCH WORKING PAPER, Department of Geography and Environment, London School of Economics and Political Science. p. 1-27, January 2012.www.ub.edu/searchproject/wp/content/uploads/2012/02/WP-1.3.pdf.

COSTA, A. B. da. Instituições e competitividade no arranjo calçadista do Vale do Sinos, Análise Econômica, Porto Alegre, ano 27, n. 52, p. 253-283, set. 2009. www.seer.ufrgs.br/AnaliseEconomica/article/download/6965/7462.

DEI OTTATI, G. The Economic Bases of Diffuse Industrialization. In International Studies of Managerial Organizations, volume $21, \quad \mathrm{n}^{\circ} \quad 1, \quad$ pp. 5357,1991.www.tandfonline.com/doi/abs/.../00208825.1991.1165654. Acesso em: 18 jun. 2019.

DEI OTTATI, G. Marshallian Industrial District: The end of an era or adaptation to the global economy? Italy: University of Florence, 2016. www.cpes.org.uk/dev/wp/content/uploads/.../Gabi Dei Ottati.pdf.

GALVÃO, L. A. Distritos industriais: potencial para o desenvolvimento regional e aumento do nível de bem-estar. (Monografia), Curso de Economia, Universidade de Brasília, 1999.

GEREFFI, G. Global Value Chains, Development and Emerging Economies. In: Research statistic and Industrial Policy Branch, Working Paper 18, /2015, Center on Globalization Governance \& Competitiveness, Duke University, United. www.unido.org/api/opentext/.../unido-file-9924327.

GIULIANI, E.; RABELLOTTI, R. Italian Industrial Districts Today: Between Decline and Openness to the Global Value Chains. In: DE MARCHI, Valentina; MARIA; Eleonora; GEREFFY, Gary (coords). Local Clusters in Global Value Chains: Linking Actors and Territories Through Manufacturing and Innovation, New York/London, Routledge. p.2132, 2018.

KNORRINGA, P. \& MEYER-STAMER, J. New Dimensions of Local Enterprise Co-operation and Development: From Clusters to Industrial Districts.ATAS Bulletin XI, "New Approaches to Science and Technology Co-operation and Capacity Building, The Hague and Duisburg, 1998. www.pdfs.semanticscholar.org/9b4aa33c5ce1bfb885ee49c90

SEVEGNANI, F.; SACOMANO, J. B. A estratégia de manufatura do setor de malharia retilínea pela análise do processo produtivo - o cluster do circuito de malhas. In: CONGRESSO NACIONAL DE EXCELENCIA EM GESTAO, julho/agosto, 2008, Niterói, RJ, Brasil www.inovarse.org/filebrowser/download/8959.

SILVA, G. S.; GARCIA, R. Fatores de competitividade na indústria de revestimentos cerâmicos: uma análise integrada dos sistemas locais de Criciúma (SC) e Santa Gertrudes (SP). In: XXV ENCONTRO NACIONAL ENGENHARIA DE PRODUÇÃO, 29 out a 01 de nov. de 2005, Porto Alegre, Brasil, ENEGEP/ABEPRO. www.abepro.org.br/biblioteca/enegep2005 enegep0704 0120.pdf 
VARGAS, G. T.; ALBERTON, A. R. O quadro recente do cluster cerâmico da Região Sul Catarinense. In: III Encontro de economia catarinense. In: ANAIS DO III ENCONTRO DE ECONOMIA CATARINENSE, Blumenau, 2009. p.1-20. http://www.ensaio.org/quadrorecente-do-cluster-cermico-da-regio-de-cricima.html

ZHANG, L.; SCHIMANSKI, S. CADEIAS GLOBAIS DE VALOR e os países em desenvolvimento. Boletim de Economia Política Internacional (BEPI), nำ18, p. 75-94, set./dez. 2014. repositorio.ipea.gov.br/handle/11058/532.

\section{NOTAS DE AUTOR}

\section{CONTRIBUIÇÃO DE AUTORIA}

Violeta de Faria Pereira - Concepção. Revisão da Bibliografia. Análise das informações bibliográficas. Elaboração do manuscrito. Revisão da versão final do trabalho.

Cláudia Andreoli Galvão - Concepção. Revisão da Bibliografia. Análise das informações bibliográficas. Elaboração do manuscrito. Revisão da versão final do trabalho.

\section{FINANCIAMENTO}

Não se aplica.

\section{CONSENTIMENTO DE USO DE IMAGEM}

Não se aplica.

\section{APROVAÇÃO DE COMITÊ DE ÉTICA EM PESQUISA}

Não se aplica.

\section{CONFLITO DE INTERESSES}

Não se aplica.

\section{LICENÇA DE USO}

Este artigo está licenciado sob a Licença Creative Commons CC-BY. Com essa licença você pode compartilhar, adaptar, criar para qualquer fim, desde que atribua a autoria da obra.

\section{HISTÓRICO}

Recebido em: 01-10-2019

Aprovado em: 01-05-2020 